\title{
Household Food Expenditures and Obesity Risk
}

\author{
Parke E. Wilde • Joseph Llobrera • Natalie Valpiani
}

Published online: 21 June 2012

(C) Springer Science+Business Media, LLC 2012

\begin{abstract}
Obesity risk depends on food energy balance. Because food and beverages are acquired primarily through purchases by household members, understanding food expenditure is central to understanding food intake and obesity risk. This paper reviews three areas of the literature that explore potential influences on food expenditure and thus obesity risk: food insecurity, food environments, and food prices. This article examines these three lines of research together, reporting key results in a comparable fashion; it focuses on recent innovations in data and research design in each area; and it includes articles that have been published since the most recent reviews. While it did not prove possible to identify a single food expenditure influence that most strongly affects obesity risk, examining the three literatures jointly highlights fertile ground for future work that combines elements of each.
\end{abstract}

Keywords Obesity $\cdot$ Body mass index $\cdot$ Expenditure $\cdot$ Food insecurity $\cdot$ Price $\cdot$ Food environment $\cdot$ Access

\section{Introduction}

Obesity risk depends on food energy balance, including energy use and energy intake [1]. For non-institutionalized

\author{
P. E. Wilde $(\bowtie) \cdot J$. Llobrera $\cdot$ N. Valpiani \\ Gerald J. and Dorothy R. Friedman \\ School of Nutrition Science and Policy, \\ 150 Harrison Avenue, \\ Boston, MA 02111, USA \\ e-mail: Parke.Wilde@tufts.edu \\ J. Llobrera \\ e-mail: Joseph.Llobrera@tufts.edu \\ N. Valpiani \\ e-mail: Natalie.Valpiani@tufts.edu
}

US populations, food and beverages are acquired primarily through purchases by household members. Foods are purchased from many sources, including grocery retailers, other retailers, restaurants, cafeterias, and vending machines. These food expenditures are influenced by tastes and preferences, food prices, household incomes, information, participation in nutrition assistance programs, and the food marketing environment. Understanding food expenditure is central to understanding obesity risk.

Food expenditure is important in at least three rapidly growing lines of research exploring the causes of the current obesity epidemic.

1. The food insecurity hypothesis. Food insecurity may affect weight through several mechanisms [2-4]. To cope with food insecurity, household members may consume cheaper, energy-dense foods, overeat when food resources are available, or overfeed vulnerable members in times of plenty in an effort to compensate for periods of food insecurity. Under the food insecurity hypothesis, obesity risk stems from not having enough economic resources for a food spending pattern that promotes health.

2. The food environment hypothesis. Households living in food deserts, characterized by the absence of supermarkets, may lack access to appealing and less energydense foods, such as fresh fruits and vegetables, at affordable prices [5]. In a variation on this hypothesis, households living in food swamps, characterized by the density of quick service restaurant options, may be overwhelmed by a marketing environment with too much inexpensive and energy-dense foods, or too great a ratio of energy-dense foods relative to affordable healthier options. Under the food environment hypothesis, obesity risk stems from poor retail options for a food spending pattern that promotes health. 
3. The food price hypothesis. In a simple version of this hypothesis, technological advances in the 20th century generated a long-term decline in real inflation-adjusted food prices, raising the quantity demanded and thus food intake [6, 7]. In a more complex version, prices of energy-dense foods fell in real terms relative to the prices of fruits and vegetables and less energy-dense foods [8]. Under the food price hypothesis, obesity risk stems from food demand choices that are influenced by counterproductive price signals.

Some recent research in this area addresses fundamental research design challenges. With observational data, it commonly is difficult to demonstrate that variation in obesityrelated outcomes is caused by variation in the main explanatory variable of interest, whether that variable is household food insecurity, or access to supermarkets, or food prices. In the face of this challenge, some studies just report crosssectional associations without making claims about causation, while other studies have developed innovative approaches toward stronger research design. Other recent research has been exploring improvements in data quality, through better measurement and data analysis.

As noted below, there have already been separate highquality literature reviews on all three topics since 2009. This article makes a new contribution in several respects: 1) it addresses these three lines of research together, restating some key results in a more comparable fashion; 2) it points out the distinct conceptualizations of the role of food spending in obesity risk; 3) it focuses on recent innovations in data and research design in each area, which may be useful for policy-relevant causal inferences in all three lines of research; and 4) it includes some newer articles that have been published since the most recent reviews.

The studies reviewed here are related to other lines of research that we ruled out of scope. We did not include the rapidly growing field of research on school food service and obesity $[9,10]$ because, in federal programs that provide a large fraction of meals for free, it is not clear that the customer's spending is central. We included research covering the effect of other nutrition assistance programs on obesity only if the research also addressed one of our three topics $[11,12 \bullet, 13,14,15 \bullet]$. We addressed aspects of the food environment related to food expenditure, such as access to food retailers and restaurants, but did not review how the food environment influences physical activity.

\section{Methodology}

We began this project with the existing literature reviews plus an extensive partial bibliography of relevant sources already in hand, collected non-systematically. We supplemented this initial bibliography with a systematic search of the PubMed database on the three lines of research. This database search retained refereed English-language empirical research articles published between 2009 and 2012 with a treatment relevant to one of the three lines of research and a reported outcome that could be expressed as an odds ratio for obesity risk or as a change in the expected value of body mass index (BMI).

1. For the food insecurity hypothesis, the search terms were food security, food insecurity, or hunger (and BMI or obesity). This search yielded 5 new articles and also repeated 6 of the 10 relevant articles in our initial bibliography.

2. For the food environment hypothesis, the search terms were food environment, food access, food desert, and food swamp (and BMI or obesity). This search yielded 4 new articles and also repeated 3 of the 18 relevant articles in our initial bibliography.

3. For the food price hypothesis, the search term was price (and BMI or obesity). This search yielded 6 new articles and also repeated 2 of the 23 relevant articles in our initial bibliography.

Our review of each empirical research article had two main components. First, we extracted reported quantitative associations between obesity and key explanatory variables, which could be treatments or economic and environmental variables. For outcomes that could be expressed as odds ratios or as a change in BMI, we tabulated the results in as comparable a format as possible (Tables 1 and 2). Second, we noted contributions to data and research design and the explicit or implicit conceptualizations of food spending.

\section{Results}

The Food Insecurity Hypothesis

\section{Background}

Food insecurity is defined as 1) the limited or uncertain availability of nutritionally adequate and safe foods, or 2) limited or uncertain ability to acquire acceptable foods in socially acceptable ways [16]. The US government produces national prevalence estimates using the Household Food Security Module in the annual Current Population Survey. The module consists of 10 survey items (for households without children) or 18 survey items (for households with children) related to experiences of food-related hardship in the previous 12 months [16]. Households are classified as food-insecure if the respondent answers affirmatively to three or more questions [17]. The survey questions ask about hardships caused by a lack of resources to acquire 
Table 1 Associations in three research literatures between selected explanatory variables and the odds of obesity, 2009-2012

\begin{tabular}{llll}
\hline Source & Treatment OR Design type
\end{tabular}

FOOD INSECURITY

Gundersen et al. [22•]

Laraia et al. [3]

\section{FOOD ACCESS}

Currie et al. [39]

Ludwig et al. [35••]

Leung et al. [58]

\section{FOOD PRICES}

Han and Powell [51]

Zhang et al. [12•]
Lohman et al. [2]

8- to 17-year-old girl lives in food-insecure household versus secure

8- to 17-year-old boy lives in food-insecure household versus secure

10 - to 15 -year-old is food-insecure versus -secure ${ }^{\mathrm{a}}$

Given that maternal stress is average: 10 - to 15 -year-old is food-insecure versus -secure ${ }^{\mathrm{a}, \mathrm{b}}$

Given that maternal stress is high: 10- to 15 -year-old is food-insecure versus -secure ${ }^{\mathrm{a}, \mathrm{b}}$

Woman is from food-insecure household versus secure ${ }^{c}$

Woman is from food-insecure household (outcome is severe obesity $\left.\mathrm{BMI}>35 \mathrm{~mm} \mathrm{~kg}^{2}\right)^{\mathrm{c}}$

Martin and Lippert [15•] Woman is from food-insecure household versus -secure

Man is from food-insecure household versus -secure

Given that child is present: woman from food-insecure household versus -secure ${ }^{\mathrm{b}}$

Given that no child is present: woman from food-insecure household versus -secure ${ }^{\mathrm{b}}$

An additional fast-food restaurant within 0.1 miles (compared to having one within 0.25 miles) ${ }^{\mathrm{d}}$

Receipt of a voucher to live in a low-poverty census tract versus no change in benefits ${ }^{\mathrm{d}}$

Presence of at least one convenience store within 0.25 mile buffer of residence versus none

Presence of at least one drug store within 0.25 mile buffer of residence versus none

Presence of at least one fast-food restaurant within 0.25 mile buffer of residence versus none

Presence of at least one produce vendor/farmer's market within 0.25 mile buffer of residence versus none

Presence of at least one full-service restaurant within 0.25 mile buffer of residence versus none

Presence of at least one supermarket within 0.25 mile buffer of residence versus none

$1 \$$ increase in fast-food price, among women ${ }^{\mathrm{d}}$

$1 \$$ increase in fast-food price, among women ${ }^{\mathrm{d}}$

$1 \$$ increase in fruit and vegetable price, among women ${ }^{\mathrm{d}}$

$1 \$$ increase in fruit and vegetable price, among women ${ }^{\mathrm{d}}$

A 1-unit increase in the fast-food price index (away-from-home burger, pizza, and fried chicken), among women

A 1-unit increase in the less-restrictive unhealthy food price index

(fast-food index + soft drink + beef + steak + sausage), among women

A 1-unit increase in the general unhealthy food price index (less restrictive

index + margarine + sugar + potatoes), among women

Given woman is SNAP participant: A 1-unit increase in the fast-food price index ${ }^{\mathrm{b}}$

Given woman is SNAP participant: A 1-unit increase in the less-restrictive unhealthy food price index ${ }^{\mathrm{b}}$

Given woman is SNAP participant: A 1-unit increase in the general unhealthy food price index ${ }^{\mathrm{b}}$

\begin{tabular}{|c|c|c|}
\hline $\begin{array}{l}1.25 \\
1.04\end{array}$ & & Cross-sectional \\
\hline $\begin{array}{l}0.99 \\
1.26\end{array}$ & & Cross-sectional \\
\hline 2.65 & & \\
\hline $\begin{array}{l}1.53 \\
2.97\end{array}$ & $* *$ & Cross-sectional \\
\hline $\begin{array}{l}1.09 \\
0.94\end{array}$ & & Cross-sectional \\
\hline 1.86 & & \\
\hline 0.61 & & \\
\hline 1.08 & $* *$ & Longitudinal \\
\hline 0.95 & & Randomized trial \\
\hline 3.38 & $* *$ & Longitudinal \\
\hline 1.26 & & \\
\hline 0.82 & & \\
\hline 2.83 & & \\
\hline 0.80 & & \\
\hline 2.18 & & \\
\hline 0.45 & $* *$ & Cross-sectional \\
\hline 0.76 & & Longitudinal \\
\hline 3.33 & $* *$ & Cross-sectional \\
\hline 0.32 & & Longitudinal \\
\hline 0.81 & & Instrumental variables \\
\hline 0.77 & $* *$ & \\
\hline 0.80 & $* *$ & \\
\hline 0.77 & & \\
\hline 0.70 & & \\
\hline 0.74 & & \\
\hline
\end{tabular}

1.04

0.99

1.26

1.53

2.97

1.09

0.94

1.08

3.38

1.26

\footnotetext{
${ }^{\text {a }}$ Outcome is a combination of overweight and obesity (BMI $\geq 85$ th percentile for age-/sex-specific reference values).

${ }^{\mathrm{b}}$ ORs calculated by literature review authors from study results. The reported interaction term was statistically significant at $P<0.05$.

${ }^{\mathrm{c}}$ Relative risk ratio.

${ }^{\mathrm{d}}$ OR based on reported mean obesity prevalence and coefficient for treatment (comparing forecast outcomes centered around current mean).

* Statistically significant at the $10 \%$ level; ** Statistically significant at the $5 \%$ level; *** Statistically significant at the $1 \%$ level.

BMI — body mass index; OR — odds ratio; SNAP — Supplemental Nutrition Assistance Program.
} 
Table 2 Associations in three research literatures between selected explanatory variables and BMI, 2009-2012

Source Treatment $\quad$ TMI

FOOD INSECURITY

Gooding et al. [14]

Tayie and Zizza [24]

Jilcott et al. [11]

\section{FOOD ACCESS}

Block et al. [40•]

Gibson [38]

Courtemanche and Carden [36•]

\section{FOOD PRICES}

Wendt and Todd $[53 \cdot \bullet]$

Powell and Han [57]

Beydoun et al. [49]
Woman is food-insecure versus secure

Man is food-insecure versus secure

Given height is below median: man is food-insecure without hunger versus secure

Given height is at or above median: man is food-insecure without hunger versus secure

Given height is below median: woman is marginally

food-insecure without hunger versus secure

Given height is at or above median: woman is marginally

food-insecure without hunger versus secure

Woman is food-insecure versus -secure

Given $<\$ 150$ in SNAP benefits per household member:

woman is food-insecure versus -secure

Given $\geq \$ 150$ in SNAP benefits per household member:

woman is food-insecure versus -secure

A 1-km increase in driving distance to the nearest fast-food restaurant

A 1-km increase in driving distance to the nearest convenience store

A 1-km increase in driving distance to the nearest grocery store

A $1-\mathrm{km}$ increase in driving distance to the nearest chain supermarket

An additional small grocery store per square mile in a person's current neighborhood (urban residents)

An additional supermarket per square mile in a person's current neighborhood (urban residents)

An additional convenience store per square mile in a person's current neighborhood (urban residents)

An additional fast-food restaurant per square mile in a person's current neighborhood (urban residents)

An additional full-service restaurant per square mile in a person's current neighborhood (urban residents)

An additional Walmart Supercenter per 100,000 county residents

A $10 \%$ price increase low-fat milk in previous quarter ${ }^{\mathrm{a}}$ A $10 \%$ price increase dark green vegetables in previous quarter $^{\mathrm{a}}$

A $10 \%$ price increase for sweet snacks in previous quarter ${ }^{\mathrm{a}}$

A $10 \%$ price increase for carbonated beverages 1 year prior $^{\mathrm{a}}$

A $10 \%$ price increase for $100 \%$ juices 1 year prior ${ }^{\mathrm{a}}$

A $10 \%$ price increase fresh/frozen starch vegetables 1 year prior ${ }^{\mathrm{a}}$

A $\$ 1$ increase in fast-food price index among men

A $\$ 1$ increase in fast-food price index among women

A $\$ 1$ increase in FV price index among men

A \$1 increase in FV price index among women

A $\$ 1$ increase in FV price index among poor women

A $\$ 1$ increase in FV price index among non-poor women

A $\$ 1$ increase in FV price for women with children present in $\mathrm{HH}$

A $\$ 1$ increase in FV price for women with no children present

A \$1 increase in fast-food price index among children aged $2-9$ years
$0.87 \quad * * \quad$ Cross-sectional

0.01

$-1.47$

$* *$

Cross-sectional

$-1.35 \quad * *$

1.88

$-0.28$

0.48

0.77

$* *$

$* *$

Cross-sectional

0.08

$-0.11$

$*$

Longitudinal

0.02

$-0.06$

$-0.02$

0.02

*

Longitudinal

$-0.03$

$-0.002$

$-0.005$

$-0.001$

0.237

Instrumental Variables

0.07

0.05

$* * *$

Longitudinal

$-.05 \quad * * *$

$-.08$

$-0.06$

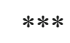

$-0.06$

$* * *$

0.07

0.26

0.27

0.62

3.56

0.40

1.10

$-0.19$

$-0.2$

Cross-sectional 
Table 2 (continued)

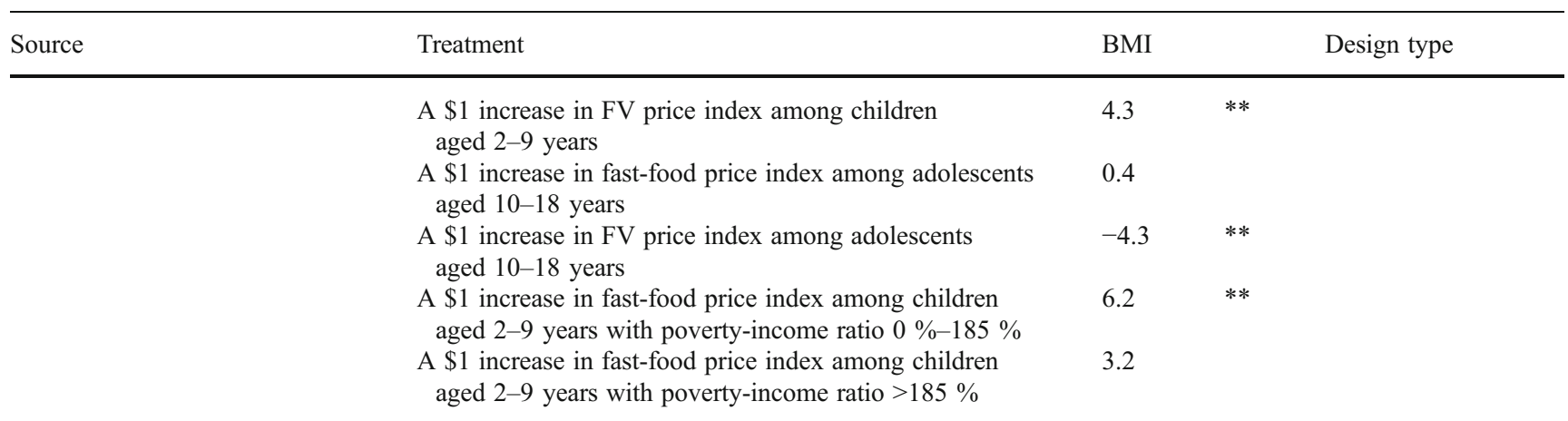

${ }^{\text {a }}$ Reported change for child BMI was based on reported percent change in the source document, converted to unit change using the average BMI measure in the sample $\left(18.5 \mathrm{~mm} / \mathrm{kg}^{2}\right)$ at the average age ( 8 years).

* Statistically significant at the $10 \%$ level; ** Statistically significant at the $5 \%$ level; *** Statistically significant at the $1 \%$ level.

BMI — body mass index; FV—fruit and vegetable; HH—household; SNAP—Supplemental Nutrition Assistance Program.

food; food insecurity is about having insufficient resources for food spending.

Because weight gain is caused by food and beverage intake that is more than sufficient for energy balance, the empirical association between insufficient resources and obesity is sometimes called a "paradox," although in fact the possible coexistence of food insecurity and obesity has long been understood [18]. Several previous reviews summarize the literature published on this association through 2010. Eisenmann et al. [19] reviewed 16 cross-sectional and 5 prospective studies conducted in children and adolescents. All of the studies demonstrated coexistence of food insecurity and overweight, but results revealed a mix of positive, negative, and null associations between them. An additional review including 42 studies [20] similarly found mixed evidence for a food insecurity-weight status association among children and little evidence for men. Among women, consistent evidence suggests a positive association between food insecurity and risk of obesity.

\section{Recent Literature}

Recent studies have used new data sources or measures of obesity and food insecurity, examined the association in specific sub-populations, and explored interaction terms or effect modifiers. One recent study also employed nonparametric analysis techniques to examine the food insecurityobesity relationship. The research confirms some previous mixed results about the association between food insecurity and risk of obesity.

Several recent studies employed measures of food insecurity and obesity that differ from the bulk of the earlier literature. Yaemsiri et al. [21] drew on the NYC Community Health Survey to assess food concern (found to be associated with obesity among white New Yorkers but not among Black, Hispanic, or Asian adults). Gundersen et al. [22•] estimated the association between household food insecurity and alternative measures of childhood weight status including BMI, waist circumference, tricep skinfold thickness, trunk fat mass, and percentage of whole body fat (no significant associations with food insecurity).

Other recent studies focused on specific populations. Laraia et al. [3] studied the food security status of pregnant women in North Carolina (finding a strong association with risk of severe obesity). Buscemi et al. [23] studied parents' acculturation scores and food security status for low-income Latino children (finding an association between both parent acculturation and food insecurity and lower child BMI, and a significant interaction effect).

Still other studies, such as the Buscemi et al. [23] study, explored mediators or effect modifiers. Lohman et al. [2] assessed the mediating effect of individual, maternal, and family stressors in a cross-sectional analysis of 1011 adolescents (finding that maternal stress enhanced the association between food insecurity and risk of overweight or obesity). For adults, Martin and Lippert [15•] built on previous research studying gender as an effect modifier for the relationship between food insecurity and risk of obesity. They explored whether it is better to treat the heavy burdens of management of the family's food supply, rather than gender itself, as the relevant effect modifier (finding that the association between food insecurity and risk of obesity is stronger for women with children than for women without children). Gooding et al. [14], however, found that the interaction between food insecurity and the presence of children had a nonsignificant effect on the BMI of both women and men. In a cross-sectional study of the 1999-2002 NHANES (National Health and Nutrition Examination Survey), Tayie and Zizza [24] only partly confirmed earlier research suggesting that height was an effect modifier (for men, food insecurity was significantly associated with lower BMI regardless of their measured height; for women, marginal food security was associated with higher 
BMI only among women below median height). Jilcott et al. [11] estimated the moderating effect of Supplemental Nutrition Assistance Program (SNAP) benefits in a convenience sample of North Carolina women. They found a positive association between food insecurity and BMI for women receiving less than $\$ 150$ in SNAP benefits per person per month, but no association among women receiving larger amounts.

One study investigated the possibility of reverse causation among adults aged 50 years and older [25]. In adjusted models, older adults categorized as Class II obese based on a waist circumference for men $\geq 49$ inches and for women $\geq 45$ inches were 2.51 times as likely to be food insecure as adults with narrower waists $(95 \% \mathrm{CI}, 1.43,4.39, P \leq 0.01)$. In older adults, the authors posit that obesity may lead to food insecurity through the effects of weight-related disability.

Finally, a recent study employed alternative nonparametric functional forms in the statistical analysis. Using data from the nationwide Panel Study of Income Dynamics (PSID), Kuku et al. [26•] found non-linear associations between the number of affirmative food insecurity responses and the risk of childhood obesity, and these associations vary by gender, race, and income level. At higher levels of food insecurity, the probability of obesity decreases markedly among boys, while rising to its highest level among girls. Their results confirm the possibility, suggested in previous work documenting an inverse U-shaped relationship [13, 27, 28], that the food insecurity-obesity relationship may be nonlinear.

\section{Looking Forward}

The recent focus on particular populations, particular effect modifiers, and non-linear functional forms, improves and extends our knowledge of the cross-sectional associations between food insecurity and obesity. Yet, the result is a plethora of statistically significant and insignificant associations whose overall thrust is difficult to characterize. Moreover, as all of the studies acknowledge, and as the Brewer et al. [25] study specifically emphasizes, we cannot describe food insecurity as the cause and risk of obesity as the outcome. Studies in the next two sections place stronger emphasis on research designs that seek to estimate the effects of the key explanatory variables on obesity outcomes, but such emphasis has not been possible to date in research on the food insecurity hypothesis.

The Food Environment Hypothesis

\section{Background}

The food environment determines the set of options available to individuals and households as they make food spending choices. Household food spending patterns influence the dietary intake of household members and, ultimately, health and weight status. Researchers have been concerned about multiple potential shortcomings of the food environment:

- Perhaps low-income neighborhoods lack food retailers;

- Perhaps retailers offering healthy food options are too far away for customers without automobiles;

- Perhaps other food services, including quick-service restaurant chains and small scale convenience stores, are more likely to be available in low-income neighborhoods;

- Perhaps the retailers present in low-income neighborhoods have low quality and high prices for healthy food options.

Much of the early research explored cross-sectional associations between the distribution of food retailers or restaurants within an area and the demographic or socioeconomic characteristics of that area [5,29]. Evidence suggests that neighborhoods that are predominantly lower income and minority have fewer supermarkets or longer distances to supermarkets [30-32]. Other studies have noted that the density and proximity of fast-food outlets tends to be higher in low-income neighborhoods [33].

Attention has since shifted toward establishing connections between the food environment and diet and health outcomes. Larson et al. [33] reviewed 54 studies and found that households with better access to supermarkets and limited access to convenience stores tended to have healthier diets and lower obesity rates. The findings on restaurant access were less consistent, but they suggested that less access to fast-food restaurants was associated with better diets and lower rates of obesity. Giskes et al.'s [34] review of the literature found a consistent association between environment and weight status. Better access to supermarkets and more limited access to fast-food restaurants were associated with lower BMI or prevalence of overweight or obesity, while higher weight status was found among those with limited supermarket access or greater accessibility to fast-food restaurants. Both literature reviews emphasized that the majority of studies were cross-sectional, and Giskes et al. [34] specifically cautioned against giving the results a causal interpretation, noting the potential importance of more general material deprivation in low-income neighborhoods. Such neighborhoods may have other relevant characteristics in addition to limited supermarket access.

\section{Recent Literature}

Recent research efforts seek to strengthen causal claims through the use of longitudinal data analysis methods, instrumental variable techniques, randomized trials, and the careful selection of key exogenous variables in research design. Even with these improvements in research design, many recent studies have had mixed results and small estimated effects. 
Some researchers have used randomized social policy initiatives to address selection bias and unobserved heterogeneity. Ludwig et al. [35•*] compared the baseline and follow-up weight status of participants in Moving to Work, a randomized US Department of Housing and Urban Development (HUD) demonstration program. Existing public housing residents in high-poverty areas were randomly assigned to receive vouchers that could be used to relocate to low-poverty areas, unrestricted vouchers that could be used to relocate to another area regardless of the poverty rate, or no new assistance. Moving from a high-poverty urban area to a low-poverty area was associated with small reductions in the prevalence of extreme obesity (BMI $>35 \mathrm{~mm} / \mathrm{kg}^{2}$ ). Through random assignment, the study had an exceptional source of independent variation in the key explanatory neighborhood location variable, but it is not possible to say if the food retail environment or some other characteristic of low-income neighborhoods is responsible for the observed results.

Other researchers have used an instrumental variables approach to estimate causal effects. Courtemanche and Carden [36 ] identified an instrument using information on the entry date and location of Walmart Supercenters and the unique geographical expansion of Supercenters centered around the Walmart headquarters in Bentonville, Arkansas. Each additional Walmart Supercenter per 100,000 residents (county-level) increased average BMI and the probability of being obese. This effect was strongest for women, lowincome married individuals, and those living in the least populated counties. They conclude that the existence of Walmart Supercenters account for $10.5 \%$ of the rise in the obesity rate in the United States since the late 1980s.

Chen et al. [37] take account of the special correlations among households who live closer to each other, finding that increased access to chain grocers was associated with lower BMI for people in low-income neighborhoods but not higher-income neighborhoods. Other studies use longitudinal data and fixed effects models to control for some of the unobserved heterogeneity. Most noteworthy are studies that use longitudinal data for both weight outcomes and food environment exposure. Using follow-up data from the $\mathrm{Na}$ tional Longitudinal Survey of Youth 1979, Gibson et al. [38] found that the density of small grocery stores was positively and significantly associated with obesity and BMI among residents of urban areas. For individuals who moved from rural to urban areas over a 2-year period, changes in neighborhood supermarket density, small grocery store density, and full service restaurant density were significantly associated with the change in BMI over that period.

Using information from the California public school system, Currie et al. [39] estimated the relationship between the change in weight status and the change in nearby fast-food restaurant availability. The presence of a fast-food restaurant within 0.1 miles of a school was associated with an increase in the fraction of students in a class who were obese relative to the presence of a fast-food restaurant within 0.25 miles. This effect accounted for a $5.2 \%$ increase in the incidence of obesity among the affected children.

Block et al. [40•] examined the long-term relationship between the food environment and weight status using data spanning 30 years from the Framingham Heart Study Offspring Cohort. Each 1-km increase in distance to the closest fast-food restaurant was associated with a decrease in BMI. In sex-stratified analyses, the association of fast-food restaurant proximity was present only for women. Other aspects of the food environment were inconsistently associated or not at all associated with BMI.

\section{Looking Forward}

Two topics that deserve further investigation are consumers' access to vehicles and their willingness to trade off retail proximity against other objectives such as lower cost and greater product variety. The US Department of Agriculture (USDA)'s 2009 Report to Congress on food deserts found that only $2.3 \%$ of American households, and $3.6 \%$ of American households living in low-income areas, lived more than a mile from a supermarket and also lacked access to an automobile [5]. Future research may distinguish households with and without automobile access when measuring the effects of the food environment.

Even with more sophisticated study design and econometric techniques, the relationship between the food environment and obesity remains mixed. Issues with selection bias and unobserved heterogeneity remain, because the food environment, neighborhood characteristics, and health and weight status of populations within neighborhoods change over time and not independently [29]. Research in this area would benefit from careful investigation of the different steps in the causal chain, by exploring relationships between the food environment and multiple outcomes in the same population. In future work, the PHRESH (Pittsburgh Hill/Homewood Research on Eating, Shopping \& Health) study will examine the effect changes in the food environment on both more proximal outcomes, like household shopping behavior, and more distal outcomes, like health and weight status, in two Pittsburgh communities before and after introduction of a supermarket in one of the sites [41]. Incorporating more micro-level data on food item availability and prices is another area to prioritize in future research.

\section{The Food Price Hypothesis}

\section{Background}

In the basic microeconomic theory of food spending, consumers maximize utility subject to a budget constraint that depends on prices and income. For normal goods, increased 
income boosts while higher prices lower the quantity demanded of a particular good. A price increase for one good may also raise or lower the quantity demanded of a second good, depending on whether the goods are respectively substitutes or complements. Higher prices for healthy foods, or lower prices for unhealthy foods, could increase the risk of obesity $[8,42,43]$. Some research has explored this association directly, mainly through models that regress a weightrelated variable on prices and income. Other research has explored it indirectly, by estimating demand elasticities and then extrapolating the implications for obesity risk based on a simulated model of the metabolic response.

Previous evidence explores potential effects of food prices on intake and obesity. Epstein et al. [44] reviewed studies that investigate the response of food and macronutrient purchases to laboratory and field-based price experiments. The purchase of less healthful foods fell as price increased while lower prices boosted purchase of healthier options. Improvement in nutrient intake was less consistent. Andreyeva et al. [45] reviewed 160 observational studies estimating demand elasticities for 16 food and beverage groups. Elasticities varied from 0.27 to 0.81 (absolute values). Finally, Powell and Chaloupka [42] reviewed evidence of food price sensitivity of weight outcomes. The effect of price was found to be small in magnitude, though more likely to produce weight change among children, lowincome individuals, and those at risk for overweight.

\section{Recent Literature}

New research has innovated in several directions: using new sources of price data, research designs, and methods for estimating the likely effects of demand responses on obesity. Whereas earlier research tended to be skeptical that higher prices for snack foods would have much influence on demand [46], some of the new research has been more optimistic that there could be a substantial demand response for certain food and beverage categories.

Several studies use cross-sectional or random-effects models. Three of these utilize Council for Community and Economic Research (C2ER, formerly known as ACCRA) data, which capture prices of 27 food prices in urban markets. Gordon-Larsen et al. [47] studied the response of adolescent fast-food intake to community-level soda and hamburger prices. Significant results were small in magnitude and price sensitivity varied by item, race, and income. Khan et al. [48] found larger effects. Using an expanded, weighted set of C2ER prices they estimated that a $10 \%$ increase in the price of fast food is associated with a $5.7 \%$ decrease in weekly frequency of fast-food consumption among 5th and 8th graders. Beydoun et al. [49] linked fast food and fruit and vegetable price indices to food intake and BMI. Price increases had significant, expected effects among children (fewer fast-food items consumed; increased BMI), but not adolescents. Additionally, Andreyeva et al. [50] used industry consumption data to estimate that a penny-per-ounce excise tax on sugar-sweetened beverages would result in a $24 \%$ annual drop in consumption, resulting in a potential per capita weight loss of $5 \mathrm{lb} /$ year.

A few studies employed the fixed-effects models to control for unobserved characteristics. Han and Powell [51] drew on the C2ER database and compared random- to fixed-effects models. In random-effect models, a $10 \%$ increase in fast-food price index was associated with an $18.8 \%$ and $20.7 \%$ decrease in the probability of obesity among women and men, respectively. However, these associations lost magnitude and significance in individual fixedeffects models. Staudigel [52] found significant, but very small price effects on BMI for 4 of 20 foods, and no price effect on obesity prevalence among Russian adults.

In contrast, Zhang et al. [12•] found evidence for a food price-obesity relationship among US female SNAP participants. A significant negative interaction term suggested that higher prices of unhealthy foods partially offset the positive association found between SNAP participation and body weight. In instrumental variable models, the unhealthy food price index and the price-SNAP interaction term remained associated with lower odds of obesity.

While most of the above studies used C2ER data, Wendt and Todd [53••] drew upon the new Economic Research Service (ERS) Quarterly Food-at-Home Price Database (QFAHPD) to show that price changes may have a lagged effect on child obesity. The QFAHPD, constructed from Nielsen Homescan data, includes frequency-weighted prices for 52 narrowly defined food groups. Wendt and Todd [53・•] combine QFAHPD with Early Childhood Longitudinal Study data in fixed-effects models. They found significant price effects for several foods and beverages, and note that for some items the previous quarter's price impacts BMI, while for others the 1-year lagged price affects weight. Estimated effects account for around $10 \%$ of annual growth for a child at the 85th percentile of BMI.

Finally, Lin et al. [54.•] advanced the literature by proposing the use of a dynamic weight loss model for estimating the impact of tax-induced beverage demand changes on obesity. This model assumes that changes in body composition during an intervention impact the energy deficit needed for continued weight loss, whereas the widely used static model assumes that a 3500-calorie energy consistently translates to $1 \mathrm{lb}$ of body weight loss. In side-by-side simulations, the static model overestimates weight loss by $63 \%$ in year 1 and $346 \%$ in year 5 .

\section{Looking Forward}

Though this research has advanced in the analytical methods used, a key limitation remains the lack of a database combining information about dietary intake, health outcomes, and 
prices. Many recent studies rely on the C2ER. This database provides prices for just 24 food-at-home and 3 food-awayfrom home items that represent indicator prices for geographic markets, not prices that individual consumers actually pay. Furthermore, some question its representativeness, as the sample focuses on urban areas and food retailers frequented by professional (upper-income) consumers [55]. In 2012, USDA/ERS will begin its new National Household Food Acquisition and Purchase Survey (FoodAPS). This survey will collect information on the price and quantity of household food purchases as well as demographic, socioeconomic, diet and health information for household members. While FoodAPS will improve researchers' ability to study the priceobesity relationship, it remains cross-sectional in design. Future research will be further strengthened by longitudinal data on diet and weight outcomes linked to changes in the food prices that individuals actually pay. Randomized price-change trials such as the forthcoming SHELf (Supermarket Healthy Eating for Life) trial conducted by Ball et al. [56] will also play an essential role in establishing causality.

\section{Conclusions}

A purpose of this article was to compare findings and methodologies across three diverse lines of research. Even with our effort to put obesity-related outcomes on a comparable scale, it did not prove possible to draw conclusions about which theory of food expenditure has the greatest impact on obesity risk. The main hurdle is that the treatments or changes in environmental variables are so diverse. It is difficult to say what number of new food retailers per county has the right scope or magnitude for a fair comparison with a $10 \%$ tax on a sugar-sweetened beverage.

Most studies focus only on one of the three hypotheses connecting food expenditure to obesity risk. The exceptions are interesting. For weight status outcomes data from the PSID, Powell and Han [57] used food price information from C2ER and food retail locations from the Dun and Bradstreet commercial database. Courtemanche and Carden [36-] offered an intriguing discussion of whether their findings for Walmart Supercenters are due to the retail chain's distinctive pricing strategy or to its role in the retail environment. Future research may fruitfully continue to combine elements from the three literatures reviewed here. For example, the food insecurity literature in the first section focuses on lack of resources for comparably expensive foods, a topic that would benefit from explicit attention to the food price variation addressed in the third section.

Many of the studies reviewed here concluded with a discussion of policy relevance. When available, we have highlighted studies that sought to identify the effects of food prices and the food retail environment on obesity-related outcomes, using research designs that go beyond just cross-sectional comparison. To the extent that research on food expenditure is intended to support policy analysis, future research in this same spirit may strengthen our knowledge about the effects of both retail environment and food prices on multiple outcomes, including both food security status and the risk of obesity.

Acknowledgments This study was supported in part by a cooperative agreement with USDA's Economic Research Service (Agreement Number \#58-5000-1-0051). The authors alone, not the funding agency, are responsible for all conclusions and any errors.

Disclosure Conflicts of interest: P.E. Wilde: has received grant support from USDA/Econ. Res. Service; J. Llobrera: None; N. Valpiani: None.

\section{References}

Papers of particular interest, published recently, have been highlighted as:

- Of importance

•. Of major importance

1. U.S. Department of Agriculture and U.S. Department of Health and Human Services: Dietary Guidelines for Americans, 2010. 7th Edition, Washington, DC: U.S. Government Printing Office, 2010.

2. Lohman B, Stewart S, Gundersen C, et al. Adolescent overweight and obesity: Links to food insecurity and individual, maternal and family stressors. J Adolesc Health. 2009;45:230-7.

3. Laraia B, Siega-Riz A, Gundersen C. Household food insecurity is associated with self-reported pregravid weight status, gestational weight gain, and pregnancy complications. J Am Diet Assoc. 2010;110:692-701.

4. Beydoun M, Wang Y. Pathways linking socioeconomic status to obesity through depression and lifestyle factors among young US adults. J Affect Disord. 2010;123:52-63.

5. Ver Ploeg M, et al. Access to Affordable and Nutritious FoodMeasuring and Understanding Food Deserts and Their Consequences: Report to Congress. Washington, DC: U.S. Department of Agriculture, Economic Research Service; 2009.

6. Chou SY, Grossman M, Saffer H. An economic analysis of adult obesity: results from the Behavioral Risk Factor Surveillance System. J Health Econ. 2004;23:565-87.

7. Lakdawalla D, Philipson T. The growth of obesity and technological change: A theoretical and empirical investigation. Cambridge: National Bureau of Economic Research; 2002.

8. Drewnowski A, Specter S. Poverty and obesity: the role of energy density and energy costs. Am J Clin Nutr. 2004;79:6-16.

9. Gleason P, Dodd A. School breakfast program but not school lunch program participation is associated with lower body mass index. J Am Diet Assoc. 2009;109:S118-28.

10. Schanzenbach DW. Do school lunches contribute to childhood obesity? J Hum Resour. 2009;44:684-709.

11. Jilcott S, Wall-Bassett E, Burke S, Moore J. Associations between food insecurity, supplemental nutrition assistance program (SNAP) benefits, and body mass index among adult females. J Am Diet Assoc. 2011;111:1741-5.

12. - Zhang Q, Chen Z, Dlawara N, Wang Y. Prices of unhealthy foods, Food Stamp Program participation, and body weight status among U.S. low-income women. J Fam Econ Iss. 2011;32:245-56. 
In this paper, the authors explore the effect on obesity of the interaction between SNAP participation and unhealthy food prices. Using panel data, they find that higher prices for unhealthy food may partially offset associations between SNAP participation and weight among women.

13. Webb A, Schiff A, Currivan D, Villamor E. Food Stamp Program participation but not food insecurity is associated with higher adult BMI in Massachusetts residents living in low-income neighbourhoods. Public Health Nutr. 2008;11:1248-55.

14. Gooding HC, Walls CE, and Richmond TK: Food Insecurity and Increased BMI in Young Adult Women. Obesity (Silver Spring) 2011, In press.

15. - Martin M and Lippert A: Feeding her children, but risking her health: The intersection of gender, household food insecurity and obesity. Soc Sci Med 2012, In press. This study argues that previously noted differences in the food insecurityobesity association are due not to gender, but rather to the gendered nature of child care. Food-insecure mothers were more likely than food-insecure fathers and child-free women to be overweight or obese.

16. National Research Council: Food Insecurity and Hunger in the United States: An Assessment of the Measure. Edited by Wunderlich G and Norwood J. Washington, DC: The National Academies Press; 2006.

17. Coleman-Jensen A, Nord M, Andrews M, and Carlson S: Household Food Security in the United States in 2010. U.S. Dept. of Agriculture, Economic Research Service 2011: 1-37.

18. Dietz W. Does hunger cause obesity? Pediatrics. 1995;95:766-7.

19. Eisenmann JC, Gundersen C, Lohman B, et al. Is food insecurity related to overweight and obesity in children and adolescents? A summary of studies, 1995-2009. Obes Rev. 2011;12:e73-83.

20. Larson N, Story M. Food insecurity and weight status among U.S. Children and Families. Am J Prev Med. 2011;40:166-73.

21. Yaemsiri S, Olson C, He K, Kerker B. Food concern and its associations with obesity and diabetes among lower-income New Yorkers. Public Health Nutr. 2011;15:39-47.

22. - Gundersen C, Garasky S, Lohman B. Food insecurity is not associated with childhood obesity as assessed using multiple measures of obesity. J Nutr. 2009;139:1173-8. The authors test the food insecurity-obesity association using multiple measures of obesity. Food-insecure children were no more likely to be obese than their food-secure counterparts across all five measures.

23. Buscemi J, Beech BM, Relyea G. Predictors of obesity in Latino children: acculturation as a moderator of the relationship between food insecurity and body mass index percentile. J Immigr Minor Health. 2011;13:149-54.

24. Tayie FA, Zizza CA. Height differences and the associations between food insecurity, percentage body fat and BMI among men and women. Public Health Nutr. 2009;12:1855-61.

25. Brewer D, Catlett C, Porter K, et al. Physical limitations contribute to food insecurity and the food insecurity-obesity paradox in older adults at senior centers in Georgia. J Nutr Elder. 2010;29:150-69.

26. - Kuku O, Garasky S, Gundersen C. The relationship between childhood obesity and food insecurity: a nonparametric analysis. Appl Econ. 2012;41:2667-77. The application of nonparametric regression techniques uncovers a significant association between food insecurity and childhood obesity not found in the commonly used parametric analysis. The associations vary across race, gender, and income and appear non-linear.

27. Hanson KL, Sobal J, Frongillo EA. Gender and marital status clarify associations between food insecurity and body weight. J Nutr. 2007;137:1460-5.

28. Wilde PE, Peterman JN. Individual weight change is associated with household food security status. J Nutr. 2006;136:1395-400.

29. Lytle LA. Measuring the food environment: State of the science. Am J Prev Med. 2009;36:S134-44.
30. Chung C, Myers S. Do the poor pay more for food? An analysis of grocery store availability and food price disparities. J Consum Aff. 1999;33:276-96.

31. Morland K, Wing S, Diez Roux A, Poole C. Neighborhood characteristics associated with the location of food stores and food service places. Am J Prev Med. 2002;22:23-9.

32. Zenk SN, Schulz AJ, Israel BA, et al. Neighborhood racial composition, neighborhood poverty, and the spatial accessibility of supermarkets in metropolitan Detroit. Am J Public Health. 2005;95:660-7.

33. Larson N, Story M, Nelson M. Neighborhood environments: disparities in access to healthy foods in the U.S. Am J Prev Med. 2009;36:74-81.

34. Giskes K, van Lenthe F, Avendano-Pabon M, Brug J. A systematic review of environmental factors and obesogenic dietary intakes among adults: Are we getting closer to understanding obesogenic environments? Obes Rev. 2011;12:e95-e106.

35. • Ludwig J, Sanbonmatsu L, Gennetian L. Neighborhoods, obesity, and diabetes-a randomized social experiment. N Engl J Med. 2011;365:1509-19. Investigators used health and weight information from participants in a randomized US HUD demonstration program to investigate the relationship between randomly assigned food environment and health and weight status. Existing public housing participants were randomly assigned to receive new vouchers for use in low-poverty neighborhoods, unrestricted vouchers, or no new benefits.

36. - Courtemanche C, Carden A. Supersizing supercenters? The impact of Walmart Supercenters on body mass index and obesity. $\mathrm{J}$ Urban Econ. 2011;69:165-81. Investigators identify an instrumental variable using information on the entry date and location of Walmart Supercenters across the United States and the unique geographical expansion of Walmart Supercenters centered around the Walmart headquarters in Bentonville, Arkansas. They use this instrument to estimate the effect of Walmart Supercenters' presence on BMI.

37. Chen S, Florax RJGM, Snyder SD. Does where you live make you fat? Obesity and access to chain grocers. Econ Geogr. 2010;86:431-52.

38. Gibson DM. The neighborhood food environment and adult weight status: estimates from longitudinal data. Am J Public Health. 2011;101:71-8.

39. Currie J, DellaVigna S, Moretti E, and Pathania V: The effect of fast food restaurants on obesity and weight gain. NBER Working Paper No. 14721, 2009. Available at http://www.nber.org/papers/ w14721. Accessed March 2012.

40. • Block JP, Christakis NA, O'Malley AJ, Subramanian SV. Proximity to food establishments and body mass index in the Framingham Heart Study offspring cohort over 30 years. Am J Epidemiol. 2011;174:1108-14. This longitudinal analysis uses weight status data spanning 30 years from the Framingham Heart Study Offspring Cohort to look at the long-term relationship between fastfood restaurant proximity and BMI.

41. RAND Corporation: PHRESH: Pittsburgh Hill/Homewood Research on Eating, Shopping \& Health. Available at http://www.rand.org/ health/projects/phresh.html. Accessed March 2012.

42. Powell LM, Chaloupka FJ. Food prices and obesity: evidence and policy implications for taxes and subsidies. Milbank Q. 2009;87:229-57.

43. Drewnowski A, Darmon N. Food choices and diet costs: an economic analysis. J Nutr. 2005;135:900-4.

44. Epstein LH, Jankowiak N, Nederkoorn C, et al. Experimental research on the relation between food price changes and foodpurchasing patterns: A targeted review. Am J Clin Nutr. 2012;95:789-809.

45. Andreyeva T, Long MW, Brownell KD. The impact of food prices on consumption: a systematic review of research on the 
price elasticity of demand for food. Am J Public Health. 2010;100:216-22.

46. Kuchler F, Tegene A, Harris JM. Taxing snack foods: Manipulating diet quality or financing information programs? Appl Econ Perspect Pol. 2005;27:4-20.

47. Gordon-Larsen P, Guilkey DK, Popkin BM. An economic analysis of community-level fast food prices and individual-level fast food intake: A longitudinal study. Health Place. 2011;17:1235-41.

48. Khan T, Powell LM, and Wada R: Fast food consumption and food prices: Evidence from panel data on 5 th and 8 th grade children. $\mathrm{J}$ Obes 2012: In press.

49. Beydoun MA, Powell LM, Chen X, Wang Y. Food prices are associated with dietary quality, fast food consumption, and body mass index among U.S. children and adolescents. J Nutr. 2011;141:304-11.

50. Andreyeva T, Chaloupka FJ, Brownell KD. Estimating the potential of taxes on sugar-sweetened beverages to reduce consumption and generate revenue. Prev Med. 2011;52:413-6.

51. Han E, Powell LM. Effect of food prices on the prevalence of obesity among young adults. Public Health. 2011;125:129-35.

52. Staudigel M. How (much) do food prices contribute to obesity in Russia? Econ Hum Biol. 2011;9:133-47.

53. •• Wendt M, Todd J (2011) The Effect of Food and Beverage Prices on Children's Weights. U.S. Dept. of Agriculture, Economic Research Service 1-29. This study links panel data with the recently developed QFAHPD to demonstrate significant price effects of healthy and less healthy foods on child BMI. The data sources enable demonstration of a lagged effect between some price changes and BMI change.

54. •• Lin BH, Smith TA, Lee JY, Hall KD. Measuring weight outcomes for obesity intervention strategies: the case of a sugarsweetened beverage tax. Econ Hum Biol. 2011;9:329-41. Lin et al. advance the literature by estimating the effect of a sugarsweetened beverage tax on obesity using a dynamic calorie-toweight model. Results show that the commonly used static model significantly overestimates weight loss from expected tax-induced reductions in energy intake.

55. Todd JE, Mancino L, Leibtag E, and Tripodo C: Methodology Behind the Quarterly Food-at-Home Price Database. U.S. Department of Agriculture, Economic Research Service 2010: 1-42.

56. Ball K, McNaughton SA, Mhurchu CN, et al. Supermarket Healthy Eating for Life (SHELf): protocol of a randomised controlled trial promoting healthy food and beverage consumption through price reduction and skill-building strategies. BMC Public Health. 2011;11:715.

57. Powell L, Han E. Adult obesity and the price and availability of food in the United States. Amer J Agr Econ. 2011;93:378-84.

58. Leung CW, Laraia BA, Kelly M, et al. The influence of neighborhood food stores on change in young girls' body mass index. Am J Prev Med. 2011;41:43-51. 